\title{
RESUMO
}

ISSN Digital: 2316-381X

ISSN Impresso: 2316-3321

DOI: 10.17564/2316-381X.2020v8n2p162-175

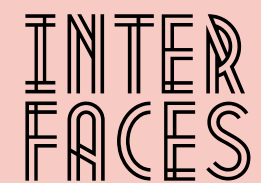

CIENTIFICAS

\section{DESTITUIÇÃO DO PODER FAMILIAR COMO CONSEQUÊNCIA DA VIOLÊNCIA DOMÉSTICA: UMA ANÁLISE CRÍTICA À LEI 13.715/2018}

FAMILY POWER DESTITUCION AS A CONSEQUENCE OF DOMESTIC VIOLENCE: A CRITICAL ANALYSIS OF THE LAW 13.715 / 2018

DESTITUCIÓN DEL PODER FAMLLIAR COMO CONSECUENCIA DE LA VIOLENCIA DOMÉSTICA: UN ANÁLISIS CRÍTICO DE LA LEY 13.715/2018

Beatriz Souza Soares ${ }^{1}$ Rita de Cássia Barros de Menezes ${ }^{2}$
0 presente trabalho discute a aplicabilidade da Lei 13.715 de 24/09/2018 em relação ao Código Penal, ao Estatuto da Criança e do Adolescente (ECA) e ao Código Civil, levando em consideração a evolução do pátrio poder até o poder familiar, analisando as alterações sofridas pelos institutos legais no que se diz respeito à destituição do poder familiar nos casos de prática de violência doméstica. Também busca analisar se tal norma traz a efetiva proteção da criança e do adolescente que são vítimas direta ou indiretamente da violência doméstica, a partir da análise prática de casos, bem como as transformações sofridas pelo Direito de Família com a evolução do poder familiar, também como a história patriarcal da família brasileira afeta a violência doméstica até os dias atuais. Com isso, utilizando-se dos princípios do melhor interesse da criança e do adolescente e da igualdade entre homens e mulheres é que se pauta a Lei, que visa não só a punição do agressor, mas também a proteção da mulher e dos filhos menores que se encontram em estado de vulnerabilidade.

\section{PALAVRAS-CHAVE}

Família. Igualdade. Poder Familiar. Violência Doméstica. 


\section{ABSTRACT}

This paper discusses the applicability of the Law 13.715 of 09/24/2018 in relation to the Criminal Code, the ECA and the Civil Code, taking into account the evolution of the patriarchal's power to family power, analyzing the changes undergone by the legal institutes in refers to the removal of family power in cases of domestic violence. It also seeks to analyze whether this norm brings the effective protection of children and adolescents who are directly or indirectly victims of domestic violence, based on the practical analysis of cases, as well as the transformations suffered by Family Law with the evolution of family power, and as well as the patriarchal history of the Brazilian family affects domestic violence to the curret days. Thus, using the principles of the best interest of the child and the adolescent and equality between men and women, the Law is governed not only by the punishment of the aggressor but also by the protection of the woman and the minor children who is in a state of vulnerability.

\section{KEYWORD}

Equality. Family. Family Power. Domestic Violence.

\section{RESUMEN}

Este documento discute la aplicabilidad de la Ley 13.715 del 24/09/2018 en relación con el Código Penal, el TCE y el Código Civil, teniendo en cuenta la evolución de la patria al poder familiar, analizando los cambios sufridos por los institutos legales con respecto a la eliminación del poder familiar en casos de violencia doméstica. También busca analizar si dicha norma brinda protección efectiva para los niños y adolescentes que son víctimas directa o indirectamente de la violencia doméstica, con base en el análisis práctico de los casos, así como los cambios experimentados por el Derecho de Familia con la evolución del poder familiar y, también, cómo la historia patriarcal de la familia brasileña afecta la violencia doméstica hasta nuestros días. Con esto, utilizando los principios del interés superior de los niños y adolescentes y la igualdad entre hombres y mujeres, se establece la Ley, que tiene como objetivo no solo castigar al agresor, sino también proteger a la mujer y los niños menores que están en un estado de vulnerabilidad.

\section{PALABRAS CLAVE}

Familia. Igualdad Poder familiar. La violencia doméstica. 


\section{INTRODUÇÃO}

O presente artigo faz uma análise da Lei 13. 715/2018, a qual entrou no ordenamento jurídico em 24 de setembro de 2018, trazendo mudanças ao Código Penal (CP), Estatuto da Criança e do Adolescente e Código Civil (CC), no que concerne à perda do poder familiar em situações de violência praticada pelo detentor de tal poder contra outrem de igual poder familiar ou filho, filha ou outro descendente.

Para tanto, faz-se necessária uma retrospectiva histórica do poder familiar, quando, no Código Civil de 1916, era denominado de "pátrio poder" e existia um modelo familiar hierarquizado e patriarcal, dando ao homem autoridade em relação não somente aos filhos, mas também à sua esposa. Foi por meio da Constituição Federal de 1988 que, ao trazer o Princípio da Igualdade entre homens e mulheres, substituiu-se tal instituto patriarcal pelo chamado poder familiar, devendo este, a partir de então, ser exercido pelo pai e pela mãe em relação aos filhos de forma igual, com os mesmos direitos e deveres, mudança esta, reafirmada pelo Código Civil atual.

Diante da constatação de que tanto a mulher como os filhos são vulneráveis dentro do grupo familiar, e, por isso, merecem maior atenção do Estado, por meio da proteção diante da ocorrência da violência doméstica, faz-se uma análise de tal prática no contexto histórico-social, bem como um estudo da incidência da violência doméstica contra a mulher e violência familiar na Cidade de Aracaju. Analisando também os possíveis impactos que tal prática pode causar no menor.

Para tanto, utiliza-se como metodologia a pesquisa bibliográfica, estudando o poder familiar e suas formas de destituição antes da Lei 13. 715/2018, bem como os aspectos da violência doméstica. Foi feita, também, uma pesquisa qualiquantitativa nas Delegacias Especializadas de Atendimento à Mulher (DEAM) e da Criança e Adolescente como Vítimas (DEACAV), analisando-se a incidência da violência familiar e seus aspectos em Aracaju-SE no período de 2017-2018.

Para uma melhor análise da Lei 13. 715/2018, buscou-se consultas aos sites do Governo Federal, livros, periódicos e redes eletrônicas, a fim de identificar as alterações trazidas para o direito no que concerne ao poder familiar, bem como entender sua aplicabilidade e eficácia.

Diante disso, o presente trabalho tem como objetivo fazer uma análise crítica da Lei 13.715/2018, atentando às modificações, não somente no Direito de Família, mas também nos outros ramos que esta Lei interfere, bem como a evolução social desde o Código Civil de 1916 até a publicação da norma jurídica referida neste artigo. Possui o intuito também de investigar se tal norma traz a efetiva proteção da criança e do adolescente que são, em muitos casos, vítimas ou que presenciam a violência doméstica, bem como sua aplicabilidade e necessidade diante de casos concretos analisados na pesquisa de campo realizada no Município de Aracaju.

\section{PODER FAMILIAR: CONTEXTUALIZAÇÃO HISTÓRICA E JURÍDICA}

Para entender o poder familiar, faz-se necessário voltar ao passado, quando o mesmo era chamado de "pátrio poder". À época do Código Civil de 1916 existia um modelo familiar patriarcal e hierar- 
quizado (GONÇALVES, 2018), ou seja, era o pai quem exercia o poder sobre os filhos, enquanto a mãe apenas cuidava dos trabalhos domésticos e dos ditos deveres matriarcais.

Segundo Carlos Roberto Gonçalves (2018, p. 411):

No aludido direito denominava-se patria potestas e visava tão somente ao exclusivo interesse do chefe de família. Esse tinha o jus vitae et necis, ou seja, o direito sobre a vida e a morte do filho. Com o decorrer do tempo restringiram-se os poderes outorgados ao chefe de família, que não podia mais expor o filho (jus exponendi), mata-lo (jus vitae et necis) ou entrega-lo como indenização (noxae deditio).

O patriarcado dava o poder de chefiar a família ao pai e, o patria potestas, como se chamava o poder familiar, visava apenas garantir o interesse do chefe familiar. Sendo assim, o pai possuía direito sobre a vida e a morte do filho, podendo expô-lo, entregá-lo como forma de indenização ou até matá-lo.

Como todos os ramos do Direito, o Direito de Família tem como base a sociedade, e com a evolução desta, passou a sofrer mudanças significativas durante o século XX, influenciado pelas revoluções Francesa e Industrial.

O advento da Constituição Federal de 1988 trouxe diversas mudanças ao Direito de Família, servido de grande referência ao poder familiar, tendo, inclusive, instituído o Princípio da Paternidade.

Uma das mudanças trazidas pela Constituição de 1988 e reafirmada no Código Civil de 2002, foi a mudança do nome "pátrio poder" para "poder familiar", isso ocorreu, pois, a responsabilidade para com os filhos passou a não ser exercida somente pelo pai, mas sim de ambos, ou seja, pai e mãe. Sendo assim, Maria Helena Diniz (2015, p. 617), conceitua o poder familiar como sendo:

[...] um conjunto de direitos e obrigações, quanto à pessoa e bens do filho menor não emancipado, exercido, em igualdade de condições, por ambos os pais, para que possam desempenhar os encargos que a norma jurídica lhes impõe, tendo em vista o interesse e a proteção filho.

Diante disto, percebemos que além da nomenclatura, a Constituição Federal trouxe para o Poder Familiar uma relação de direitos-deveres, aos pais, que por um lado possuem autoridade sobre os filhos (poder de mandar), os quais têm o dever da obediência e, por outro garantir a necessidade natural que todos precisam durante a infância, tais quais: criação, educação, amparo, defesa, além de alguém que cuide dos seus interesses, regendo sua pessoa e bens (DINIZ, 2015).

Desse modo, preceitua o jurista Carlos Roberto Gonçalves (2018, p. 412):

[] o poder familiar nada mais é do que um munus público, imposto pelo Estado aos pais, a fim de que zelem pelo futuro de seus filhos. Em outras palavras, o poder familiar é instituído no interesse dos filhos e da família, não em provimento dos genitores [...].

Podemos perceber nesta afirmação uma grande evolução no poder familiar, o qual antes beneficiava ninguém além do chefe da família, o pai, que possuía o jus vitae et necis e, agora o foco é o 
bem-estar dos filhos e da família como um todo, tendo para isso, a necessidade da participação de ambos os pais no exercício dos direitos-deveres constituídos neste poder.

Além da Constituição Federal de 1988, outro instituto de extrema importância para a modificação do poder familiar foi o Estatuto da Criança e do Adolescente (ECA), que trouxe a ideia de proteção no lugar de submissão.

Diante o exposto, o poder familiar caracteriza-se por constituir um múnus público, isto é, o poder familiar é um direito-função e um poder-dever, tendo os pais autoridade sobre os filhos e ao mesmo tempo obrigações para com estes. Há ainda que se destacar que o poder familiar também se caracteriza pela relação de autoridade entre pais e filhos, que cria uma relação de obediência dos filhos para com os pais, tendo os genitores o poder de mandar e os filho o dever de obedecer.

O poder familiar é ainda inalienável e irrenunciável, não podendo os pais abrir mão dele, nem o transferir a outrem de forma gratuita ou onerosa, por se tarar de parte do estado das pessoas e, sendo assim, qualquer convenção em que o pai ou a mãe abdiquem desse poder, será nula (GONÇALVES, 2018).

Outra característica é a imprescritibilidade, visto que, como preceitua Maria Helena Diniz (2015), do poder familiar “[...] não decaem os genitores pelo simples fato de deixarem de exercê-lo; somente poderão perdê-lo nos casos previstos em lei”. Sendo ainda incompatível com a tutela, não podendo ser nomeado tutor se o poder familiar dos pais não tiver sido suspenso ou destituído.

Como exposto anteriormente, o poder familiar engloba direitos e deveres dos pais para com os filhos, os quais são enumerados pelo Art. 1634 do Código Civil:

Art. 1.634. Compete a ambos os pais, qualquer que seja a sua situação conjugal, o pleno exercício do poder familiar, que consiste em, quanto aos filhos:

I - dirigir-lhes a criação e a educação;

II - exercer a guarda unilateral ou compartilhada nos termos do art. 1.584;

III - conceder-lhes ou negar-lhes consentimento para casarem;

IV - conceder-lhes ou negar-lhes consentimento para viajarem ao exterior;

$V$ - conceder-lhes ou negar-lhes consentimento para mudarem sua residência permanente para outro Município;

VI - nomear-lhes tutor por testamento ou documento autêntico, se o outro dos pais não lhe sobreviver, ou o sobrevivo não puder exercer o poder familiar;

VII - representá-los judicial e extrajudicialmente até os 16 (dezesseis) anos, nos atos da vida civil, e assisti-los, após essa idade, nos atos em que forem partes, suprindo-lhes o consentimento;

VIII - reclamá-los de quem ilegalmente os detenha;

IX-exigir que lhes prestem obediência, respeito e os serviços próprios de sua idade e condição.

Além de regular a relação pessoal, o Código Civil, regulamenta também a administração e usufruto dos bens dos filhos, em seus Arts. 1.689; 1.690 e 1.693, tornando os pais os administradores legais dos patrimônios dos filhos menores, podendo usufruir destes, porém, não podem praticar atos que possam gerar uma diminuição patrimonial, tais como alienação, doação. 


\subsection{A DESTIRUIÇÃO DO PODER FAMILIAR NO CÓDIGO CIVIL DE 2002}

A extinção do poder familiar pode ocorrer por duas formas: causas naturais ou por decisão judicial. 0 art. 1.638 do Código Civil lista como formas de extinção natural a morte dos pais ou do filho, emancipação, maioridade, adoção e decisão judicial.

A perda ou destituição do poder familiar constitui, junto com a suspensão do poder familiar, uma sanção dada aos pais por causarem uma infração ao dever genérico de exercer a patria potestas de acordo com as normas regulamentares que visam atender ao melhor interesse do menor (GONÇALVES, 2018).

Segundo Silvio Rodrigues (2004, p. 368-369), tais sanções:

[] têm menos um intuito punitivo aos pais do que o de preservar o interesse dos filhos, afastando-os da nociva influência daqueles. Tanto assim é que, cessadas as causas que conduziram à suspensão ou a destituição do poder paternal podiam ser devolvido aos antigos titulares.

Considerada a forma mais grave de sanção, a destituição do poder familiar somente pode ser realizada mediante decisão judicial que, em regra, possui caráter permanente, podendo, porém ser restituido, Segundo Maria Helena Diniz (2015, p. 638) caso provada a regeneração do genitor ou se desaparecida a causa que o determinou.

Como visto anteriormente, aos pais, é incumbido o dever de sustento, guarda e educação dos filhos e, diante disto, o ECA prevê que caso tais deveres e direitos do menor sejam ameaçados por falta, omissão ou abuso dos pais, caberá a aplicação de medidas de segurança à criança e ao adolescente, conforme os Arts. 98, II e 101, ambos do referido Estatuto. Nesse caso, será de competência da Justiça da Infância e da Juventude conhecer a ação de destituição do poder familiar, a qual pode ser promovida pelo outro genitor, por um parente, pelo próprio menor ou, caso seja impúbere, por quem tiver sua guarda ou Ministério Público (DINIZ, 2015).

A destituição do poder familiar encontra suas hipóteses no Art. 1.638 do CC, sendo elas: castigar imoderadamente os filhos; deixar o filho em abandono; praticar atos contra a moral e os bons costumes; reincidir, reiteradamente, nas causas que geram a suspensão do poder familiar, quais sejam, de acordo com o Art. 1.637 do CC, “ abusar de sua autoridade, faltando aos deveres a eles inerentes ou arruinando os bens dos filhos" e na prática de crimes puníveis com mais de dois anos de prisão.

Assim, a destituição, é mais uma forma de proteção ao interesse do menor, do que uma punição, visto que é utilizada para garantir o bem-estar da criança elou adolescente, ao passo que o afastamento do genitor faz com que a situação nociva em que aquele estava inserido cesse, podendo o poder familiar ser restituído caso, comprovado o fim da causa da destituição, o Juiz entenda ser para o melhor interesse do menor.

\section{VIOLÊNCIA DOMÉSTICA E SUA INCIDÊNCIA EM AMBIENTES COM CRIANÇASE ADOLESCENTES}

Para entendermos as circunstâncias da violência doméstica, faz-se necessário enxergar a sociedade machista em que vivemos, na qual as mulheres são moldadas para serem gentis, usar a sabedo- 
ria e demonstrar seus sentimentos, enquanto os homens são ensinados a ser forte, usar a força para resolver situações. São nestes moldes que surge a violência doméstica.

Portanto, é importante, destacar as diferenças entre sexo e gênero, tendo essa discussão sido introduzida na sociedade em 1963 pelo psicanalista estadunidense Robert Stoller, o qual passou a afirmar que sexo está vinculado à biologia, ou seja, hormônios, genes, sistema nervoso e morfologia, enquanto gênero, tem relação com a cultura e varia de acordo com o momento histórico, lugar e classe social.

Antes disso, a antropóloga, também dos Estados Unidos, Margaret Mead, na década de 1930, foi pioneira ao mostrar que os traços que criam a noção de feminilidade e masculinidade são aprendidos desde o nascimento, ou seja, o caráter de construção cultural da diferença sexual ocorre por meio da "socialização" (PISCITELLI, 2009).

Segundo Lilia Guimarães Pougy (2010, p. 79-80):

A violência de gênero é o resultado da dominação- exploração de mulheres ao longo da história, perpetrado por sujeitos - homens e mulheres - que potencializam a eficácia da ordem vigente na produção massificada de pessoas - homens e mulheres - para operarem no nível imediato, contudo, incapacitadas para estabelecerem os nexos entre os fatos e suas origens macroscópicas e microscópicas. 0 solo fértil para a violência de gênero são as desigualdades sociais.

Diante o exposto, podemos perceber que a violência doméstica decorre de uma série de discriminações de gênero perpetradas na sociedade ao longo do tempo. Com isso, entende-se que esta ocorre por etapas, como ameaças, imposição de regras, xingamentos, entre outros. Dessa forma, ao chegar nas vias de fato, a mulher está extremamente vulnerável, fragilizada e "controlada" pelas circunstâncias que não se sente vítima e sim merecedora da "punição", ou entende que se trata de um problema familiar facilmente resolvido por meio de um diálogo.

A violência doméstica, assim como Alice Bianchine afirma em suas obras, em regra, ocorre em três fases: fase de tensão, vase do ataque violento e a fase da lua de mel. A primeira fase é aquela que começa uma espécie de crise no relacionamento, geralmente o agressor começa, com pequenas crises de ciúmes, injúrias e ameaças sentimentais, de forma sutil, criando uma dependência emocional na vítima e diminuição da sua autoestima. Já a segunda fase, é a qual ocorre à agressão propriamnete dita, geralmete física e que a prática da violência é realmente levada aos órgãos competentes de proteção.

A terceira e última fase é a da lua de mel, nesta o agressor se desculpa e a vítima, acreditando que não vai mais acontecer, o perdoa. Nesse período o agressor se mantém calmo e amoroso, com a promessa de mudar.

Porém a essas três fases formam um ciclo, se repetindo inúmeras vezes, em vista da dominação exercida pelo homem sobre a mulher, por meio de pequenas ações na primeira fase mencionada, que faz com que ocorra a inversão da culpa, onde a vítima acredita, com sua autoestima fragilizada, que a agressão sofrida foi culpa dela, que de alguma forma provocou, assim como aduz Valéria Diniz Scarance (2015, p. 129), ao afirmar: 
[...] No processo de denominação exercido pelo homem, o agressor introduz na vítima a sensação de que a conduta dela desencadeou a violência. A mulher, dominada, subjugada e com baixa autoestima, não se enxerga como vítima e toma para si a responsabilidade do ato agressivo.

A Lei Maria da Penha possui um aspecto misto preventivo-repressivo, visando, não somente prevenir a violência doméstica, mas também romper este ciclo, possibilitando ao Estado uma intervenção adequada, devendo as autoridades possuir capacitação para conhecer as fases da violência praticada no âmbito familiar e entender que a retratação na fase de lua de mel não significa que o conflito foi solucionado (FERNANDES, 2015).

É perceptível que somente a punição não reduz a prevenção da violência doméstica, nem sua diminuição, assim como aduz Romagnoli (2009, p. 117), ao dizer que:

Centrar-se somente na pena e na punição, com um endurecimento do direito criminal, por si só não garantem saídas e nem a diminuição da violência doméstica. Em contrapartida, essa postura desmobiliza esforços na construção de outras políticas para lidar com esse tipo de violência.

É preciso compreender que a violência doméstica está inserida em um contexto cultural e social, como afirma a autora Valéria Diniz Scarance (2015), reflete uma conduta apreendida, portanto, para sua efetiva prevenção, é necessário que seja feita uma reeducação do agressor, pois a partir daí, não haverá uma mudança meramente processual e sim comportamental.

É certo que na maioria dos casos, a violência doméstica é cometida pelo parceiro, seja ele marido, convivente, namorado ou ex e a vítima, em sua maioria, trata-se de mulheres jovens adultas. Porém, a Lei Maria da Penha protégé, também, os idosos, crianças e adolescentes, considerados hipossuficientes e protegidos pela Constituição Federal.

Por meio da análise de 459 Inquéritos Policiais dos anos de 2017/2018 na Delegacia Especial de Atendimento à Mulher (DEAM) de Aracaju, foi possível constatar que em aproximadamente $40 \%$ dos casos registrados, a violência doméstica é cometida pelo companheiro, marido ou namorado, durante o relacionamento ou motivados pelo término.

Desse percentual, ficou constatado que em 206 casos o casal possui filhos menores de 18 anos, e destes $53 \%$ presenciou a agressão, em $14,56 \%$ dos casos tendo sido agredido, em 13,9\% apartado ou pelo menos tentado conter a agressão.

Diante dos dados apresentados, é possível notar uma quantidade significativa de crianças elou adolescentes que de forma direta ou indireta sofreram violência perpetrada pelo seu pai em face da mãe, o que pode ocasionar diversos traumas.

Em controvérsia, faz-se importante questionar se todo autor de violência doméstica neste âmbito é necessariamente um mau pai, pois como dito anteriormente, esse tipo é uma violência de gênero, culturalmente inserida na sociedade, acreditando-se, ainda que em parte, na submissão da mulher e da sua fragilidade perante o autoritarismo e a força masculina. 
Além disso, foram pesquisados 214 Inquéritos Policiais na Delegacia Especial de Atendimento à Criança e Adolescente (DEACAV) de Aracaju, também nos anos de 2017/2018. E dentre os procedimentos analisados ficou constatado que $75 \%$ são casos de violência doméstica praticada pelo pai ou padrasto contra o menor.

A partir dos dados aqui expostos, questiona-se se a influência que a agressividade do genitor pode trazer para o seu filho ou filha, pois, como exposto, comportamento violento é apreendido, podendo tornar o menor em um homem agressor, ou sua filha em uma mulher fragilizada e submissa.

No caso do menor ser do sexo feminine, crescer num ambiente violento e opressor contra sua genitora, pode fazer com que ela acredite que tal atitude é normal e a tendência é que na vida adulta ela também se torne uma vítima da violência doméstica, por crer que por ser mulher, deve obedecer ao homem, tornando-se submissa para não ter que passar pelo que sua genitora passou.

Assim, como o ambiente violento pode afetar a criança e o adolescente, criou-se a Lei 13.715/2018, que regulamenta a perda do poder familiar nos casos de violência doméstica.

\section{ANÁLISE CRITICA À LEI 13.715/2018}

Em 24 de setembro de 2018, foi sancionada a Lei 13.715/2018, a qual dispõe sobre a perda do poder familiar pelo autor de crimes contra outrem que possui o mesmo poder ou contra filho, filha ou outro descendente, como forma de combater a violência doméstica, protegendo, principalmente, os grupos vulneráveis, tais quais, mulheres e os filhos menores, pois, não faz sentido manter o poder familiar de quem atente contra as quais, ou sobre as quais, tal poder é exercido. Assim como foi afirmado no relatório da Comissão de Direitos Humanos:

[] cuida-se, enfim, de reafirmar que o poder familiar é instituído em favor da família e de seus membros, e não uma liberdade absoluta para cometer quaisquer violências ou iniquidades contra a própria família. Reconhecer isso é uma questão de mínimo bom-senso, pois a dignidade das pessoas, inclusive mulheres e crianças, não pode estar sujeita aos impulsos violentos e arbitrários de ninguém.

A Lei em questão trouxe alterações ao Código Penal, ao Código Civil e ao Estatuto da Criança e do Adolescente. No primeiro, o Art. $2^{\circ}$ da Lei 13.715/2018, deu nova redação ao inciso II do Art. 92, sendo, primeiramente, alterada a expressão "pátrio poder" para "poder familiar", atualizando assim o Código Penal, que usava um termo ultrapassado, já que, como visto anteriormente, é um conjunto de direitos e deveres de ambos os pais com relação aos filhos menores.

De acordo com Parecer de quando tal Lei era apenas um projeto (Projeto de Lei $n^{0} 13 / 2018$ ), a relatora Marta Suplicy (2018, on-line), afirmou que:

0 art. $2^{\circ}$ do projeto busca alterar o inciso II do caput do art. 92 do Código Penal, para dispor que será um dos efeitos específicos da sentença penal condenatória a incapacidade 
para o exercício do poder familiar, tutela ou curatela nos crimes dolosos sujeitos à pena de reclusão cometidos contra filho ou filha ou outro descendente, tutelado, curatelado ou outrem igualmente titular do mesmo poder familiar.

Diante de tal afirmação, percebe-se que a maior mudança legislativa foi a inclusão do crime doloso sujeito a pena de reclusão cometido contra outrem titular do mesmo poder familiar. Ou seja, a partir de setembro de 2018, os que forem condenados por crimes com as características acima descritas, também sofrerão os efeitos da incapacidade para o exercício do poder familiar.

A alteração ao Código Penal amplia os efeitos da sentença penal condenatória, alcançando a incapacidade para o exercício do poder familiar. Ressalta-se que tal efeito não é automático da condenação, ele deverá ser reconhecido na sentença de forma fundamentada, conforme relatório parecer do Projeto de Lei $n^{0} 13.715 / 2018$ de 2018.

Por sua vez, o art. $3^{\circ}$ da Lei 13.715/2018, alterou o $\$ 2^{\circ}$ do Art. 23 do Estatuto da Criança e do Adolescente o qual dizia que "A condenação criminal do pai ou da mãe não implicará a destituição do poder familiar, exceto na hipótese de condenação por crime doloso sujeito à pena de reclusão contra o próprio filho ou filha".

Ou seja, a perda do poder familiar era uma exceção, somente em caso de condenação contra filho ou filha, admitido sua destituição. Tal raciocínio se manteve com a nova Lei, o que ela fez foi acrescentar que a violência contra outrem igualmente titular do mesmo poder familiar e outro descendente também implicariam na perda de tal poder.

O Código Civil., já previa a condenação de crime doloso como motivo para a suspensão do poder familiar no Art. 1.637, parágrafo único, tendo como justificativa a incompatibilidade do regime fechado com o exercício do poder familiar e não a natureza do crime. Por isso e diante da omissão do Art. 1.638, em relação a crime cometido contra filho ou outro descendente e outrem de igual poder familiar, foi proposta a alteração da Lei acrescentado o parágrafo único ao artigo 1.638, que diz:

Parágrafo único: Perderá também por ato judicial o poder familiar aquele:

I - praticar contra outrem igualmente titular do mesmo poder familiar:

a) homicídio, feminicídio ou lesão corporal de natureza grave ou seguida de morte, quando se tratar de crime doloso envolvendo violência doméstica e familiar ou menosprezo ou discriminação à condição de mulher;

b) estupro ou outro crime contra a dignidade sexual sujeito à pena de reclusão;

II - praticar contra filho, filha ou outro descendente:

a) homicídio, feminicídio ou lesão corporal de natureza grave ou seguida de morte, quando se tratar de crime doloso envolvendo violência doméstica e familiar ou menosprezo ou discriminação à condição de mulher;

b) estupro, estupro de vulnerável ou outro crime contra a dignidade sexual sujeito à pena de reclusão.

É importante observar que o dispositivo indica que "perderá também por ato judicial”, isso quer dizer que a perda do poder familiar pode ser determinada por decisão judicial do juízo cível, ou seja, 
não há necessidade de haver uma sentença penal condenatória para que o juizado cível determine tal medida, ao contrário do que dispõe o art. 92 do CP, pois na esfera penal é preciso haver a condenação já a destituição do poder familiar, nesta seara, é apenas um possível efeito.

Faz-se importante analisar a observação acima apresentada, se o juizado cível irá determinar tal perda, já que não há comprovação do cometimento do crime, nem o juízo é competente para analisar o mérito da infração pena. Resta deduzir que a medida de destituição do poder familiar do agressor, será de cunho similar à tutela de urgência, justificada pela gravidade do ato infracional cometido pelo genitor e o risco que tal conduta proporciona ao menor.

Diante a análise da Lei 13.715/2018, percebe-se que se criou uma dicotomia entre o Estatuto da Criança e do Adolescente e o Código Civil, ao passo que para o Estatuto, a lei previu que a prática de qualquer crime doloso sujeito a pena de reclusão pelo genitor contra a genitora, importará na destituição do poder familiar do autor do tipo penal. Já no Código Civil, ela foi menos severa, pois, neste Diploma, não basta praticar crime doloso sujeito a pena de reclusão, mas sim os requisitos listados no parágrafo único do Art. 1638.

O que ocorre é que, à luz no Código Civil, mesmo que o sujeito pratique reiteradas vezes um crime em contexto de violência doméstica, mas que não esteja elencado no dispositivo legal, não incidirá na destituição do poder familiar.

Por meio da pesquisa de campo realizada na Delegacia Especial de Atendimento à Mulher de Aracaju constatou-se que os crimes de maior incidência são justamente os crimes contra honra e lesão corporal, este em sua maioria de natureza leve. Isso significa que, diante do previsto na Lei, para o Código Civil, a maioria dos casos pouco importam para a aplicação da perda do poder familiar, pois não se constituem em homicídio, feminicídio, lesão corporal de natureza grave ou seguida de morte, estupro ou outro crime contra a dignidade sexual.

Já na DEACAV o crime mais cometido é o tipificado no Art. 136 do CP, de expor a perigo a vida ou a saúde do menor que esteja sob a responsabilidade. 0 segundo mais praticado é o de estupro de vulneráveis, sendo este $20 \%$ dos casos.

Na pesquisa, fez-se importante constatar que em $25 \%$ dos casos, a violência é cometida pelo padrasto. Diante dessa análise, surgiu o questionamento da solução para tais casos já que, geralmente, neste tipo de relação, embora haja o convívio diário, não existe o poder familiar e a Lei 13.715/2018, não faz nenhuma previsão em relação a este conflito.

De fato, o melhor para os filhos, em regra é ficar com seus pais. A família possui um papel importante no desenvolvimento das crianças e adolescentes e a convivência com ela é um direito que integra a condição humana. Porém, tais disfunções repercutem diretamente na vida e na saúde das crianças, que são pessoas em desenvolvimento, como salienta o ECA, "sendo do interesse da sociedade e do Estado o desenvolvimento biopsicológico da população infanto-juvenil em condições de normalidade" (BRANCHER,1997, p. 69; AZAMBUJA, 2006, p. 9).

Como já explanado, o poder familiar é um múnus público fiscalizado pelo Estado, por conseguinte, se os pais não o exercem de acordo com o estabelecido pelas normas, tais quais o Estatuto da Criança e do Adolescente, Código Civil, Código Penal e até mesmo na Constituição Federal, poderão ser afastados do convívio dos filhos, assim como agora determinado pela Lei 13.715/2018. 


\section{CONSIDERAÇÕES FINAIS}

A sociedade brasileira tem passado por uma grante evolução no sentido de igualdade de direitos entre homens e mulheres, principalmente no seio familiar, no qual à època do pátrio poder o marido possuia autoridade exclusiva sobre os filhos e a prórpia esposa.

Após o advento da Constituição de 1988, que trouxe ao ordenamento jurídico o Princípio da Igualdade, homens e mulheres passaram a ter os mesmo direitos e deveres, incluisive diante dos filhos. Embora tenha sido um grande avanço social, percebe-se que apesar dessa igualdade ser garantida legalmente, não significa que ela esteja garantida na prática, visto que a violência doméstica continua crescente.

Tal violência é o espelho de uma sociedade machista, na qual o homem se aproveita de sua força bruta para estabelecer uma relação de poder.

Embora a nova Lei fale de modo geral, que as regras de destituição do poder familiar nela impostas se aplicam a qualquer um dos detentores de tal poder, ou seja, tanto para a mãe quanto para o pai, é indiscutível que um dos principais propósitos da Lei seja a punição do autor da violência doméstica, visando o bem estar dos filhos.

O próprio projeto que originou a Lei 13.715/2018 usou como justificativa para a sua criação, o crescimento alarmante da violência doméstica no país, objetivando não somente proteger as mulheres vítimas, mas também os filhos que são expostos ao ambiente degradante de violência.

Diante da pesquisa realizada nas Delegacias de Especiais de Atendimento à Mulher (DEAM) e da Criança e Adolescente com vítimas (DEACAV), pode-se concluir que a Lei faz-se necessária no Município para a proteção dos menores, visto que o número de crianças que são vítimas da violência doméstica, seja de forma direta ou indireta (como expectadores), é alarmante.

Entretanto, depara-se com a problemática da quantidade de agressões cometidas por entes que não possuem tal poder, a exemplo dos padrastos. Nesses casos, a solução será apenas encontrada na esfera penal, já que nesta relação não há o poder familiar, não havendo, por consequencia, obrigação civil.

É fato que a família é um direito fundamental que integra a condição humana, prevista na Constituição Federal, além de desempenhar um papel essencial na formação e no desenvolvimento da criança e do adolescente. Assim, as disfunções causadas pela violência doméstica repercutem diretamente na vida e na saúde dos menores por serem pessoas ainda em desenvolvimento.

A estrutura familiar por ser algo vital, deve ser estável, equilibrada e, diante do cenário de desigualdade e violência justifica-se a destituição do poder familiar.

\section{REFERÊNCIAS}

AZAMBUJA, Maria Regina Fay de, Violência Sexua Intrafamiliar: é possível proteger a criança. v. 5, n. 1, 2006. 
BIANCHINI, Alice. A violência política como uma das formas de violência de gênero, 2014.

Disponível em: https://professoraalice.jusbrasil.com.br/artigos/143456023/a-violencia-politicacomo-uma-das-formas-de-violencia-de-genero. Acesso em: 6 mar. 2019.

DINIZ, Maria Helena. Curso de direito civil brasileiro: direito de família. 30. ed. São Paulo: Saraiva, 2015.

FERNANDES, Valéria Diez Scarance. Lei Maria da Penha: o processo penal no caminho da efetividade: abordagem jurídica e multidisciplinar. São Paulo: Atlas, 2015.

GONÇALVES, Carlos Roberto. Direito civil brasileiro: direito família. 15. ed. São Paulo: Saraiva Educação, 2018

PISCITELLI, Adriana. Diferenças, igualdade. São Paulo: Berlendis \& Vertecchia, 2009.

POUGY, Lilia Guimarães. Desafios políticos em tempos de Lei Maria da Penha. Rev. Katál, Florianópolis, v. 13, n. 1, jan.-jun. 2010.

RODRIGUES, Silvio. Direito civil, cit. V. 6, 2004. p. 368-369.

ROMAGNOLI, Roberta Carvalho. Várias Marias: efeitos da Lei Maria da Penha nas delegacias. Universidade Católica de Minas Gerais, Belo Horizonte-MG, maio-ago. 2009.

SUPLICY, Marta. Parecer sobre o projeto de Lei n⿳0 13/2018. Disponível em: https://legis.senado.leg.br/ sdleggetter/documento?dm=7740695\&ts=1553270303950\&disposition=inlie. Acesso em: 5 abr. 2019. 
1 Graduada em Direito na Universidade Tiradentes - UNIT. E-mail: beatriz.s.soares@hotmail.com

2 Doutora em Direito Político e Econômico pela Mackenzie; Mestre em Direitos Humando pela Universidade Tiradentes - UNIT; Graduada em Direito na Universidade Tiradentes - UNIT; Professora do departamento de Direito da Universidade Tiradentes- UNIT.

E-mail: ritacassiamenezes@uol.com.br

\section{(). (1) (2)}

Este artigo é licenciado na modalidade acesso abertosob a Atribuição-Compartilhalgual CC BY-SA

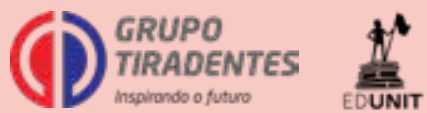

